Article

\title{
Comparison of Material Properties of SCC Concrete with Steel Fibres Related to Ingress of Chlorides
}

\author{
Petr Lehner ${ }^{1, *} \mathbb{D}$, Petr Konečný ${ }^{1} \mathbb{C}$ and Tomasz Ponikiewski ${ }^{2}$ \\ 1 Department of Structural Mechanics, Faculty of Civil Engineering, VSB-Technical University of Ostrava, \\ Ludvíka Podéště 1875/17, 70833 Ostrava-Poruba, Czech Republic; petr.konecny@vsb.cz \\ 2 Department of Building Materials and Processes Engineering, Faculty of Civil Engineering, \\ Silesian University of Technology, Akademicka 2A, 44-100 Gliwice, Poland; Tomasz.Ponikiewski@polsl.pl \\ * Correspondence: petr.lehner@vsb.cz; Tel.: +420-597-321-391
}

Received: 23 February 2020; Accepted: 18 March 2020; Published: 20 March 2020

check for updates

\begin{abstract}
The paper focuses on the evaluation of chloride ion diffusion coefficient of self-compacting concrete with steel fibre reinforcement. The reference concrete from Ordinary Portland Cement (OPC) and Self-Compacting Concrete (SCC) with several values of added steel fibres- $0 \%, 1 \%$ and $2 \%$ of weight-were cast in order to investigate the effect of fibres. The three procedures of diffusion coefficient calculation are presented-rapid chloride penetration test, accelerated penetration tests with chloride as well as the surface measurement of electrical resistivity using Wenner probe. The resulting diffusion coefficients obtained by all methods are compared and evaluated regarding the basic mechanical properties of concrete mixtures.
\end{abstract}

Keywords: SCC-SFR; chlorides; diffusion; mechanical properties; concrete

\section{Introduction}

Self-compacting concrete (SCC) [1,2] allows the simplification of concrete processing technology and the production of complex cross-sections and structural shapes. The difference compared to standard concrete is mainly in mixture composition. The proportion of cement and small aggregate is higher, and the amount of plasticizer is significantly greater. The basic properties and advantages of self-compacting concrete are mentioned in [3-6].

Other options for improvement of the mechanical properties of concrete is the use of steel fibres $[7,8]$. The selection of quantity and type of fibres depends mainly on the purpose of application and is a matter of intensive research [9-11]. Due to this, there are also several special tests for steel fibre reinforced concrete (SFRC), which are codified in recommendations and national standards [12,13]. A strong emphasis on the correct description of the material properties is important [14].

The application of self-compacting concrete (SCC) [5] brings simplification of the concrete processing technology due to the lack of need for vibration. Improved properties are achieved by modification of the formula, i.e., by appropriate use of aggregate, cement content and plasticizers [1]. Another rapidly growing area of concrete technology is steel fibre reinforced self-compacting concrete (SCC-SFR), which is classified within the group of composites that combine conventional typical structural concrete and fibres [15-17].

The purpose of the use of fibres is that it eliminates one of the greatest concrete disadvantages-low tensile strength. Fibre concrete application examples can be found particularly in tunnel lining, industrial floors, foundations, or structural elements of carrier systems. The most demanding use is in the latter group, where it is also necessary to find a suitable design procedure while providing enough reliability and safety of the structure. These may be for instance cases of lightweight structural elements where fibres are to eliminate shear destruction/failure. Input parameters of the calculation, 
fibre concrete properties are verified mainly by laboratory testing included in suggestions, standards, and design code [12,13]. It is well known that electrical properties are influenced by conductive materials. Thus, it is interesting to record the electrical conductivity values of SCC-SFR mixtures.

Furthermore, the development of tools for predicting the durability of concrete structures that help to develop durable concrete and construction systems is useful. Increased focus on higher durability helps maintain the required level of safety and maintenance for a longer period of time, which saves the cost related to premature repair and reconstruction [18,19]. A correct description of the properties of the composite materials can be combined with modelling of structures within several available models [20-23].

The article aim is to determine and extend the knowledge about the properties of self-compacting concrete with steel fibre reinforcement mixture with a fibre content of $0 \%, 1 \%$, and $2 \%$. This is due to their use in the field of reinforced concrete structures exposed to chlorides, where it is necessary to properly model diffusion processes [24-27]. Moreover, three methods for evaluation of the diffusion coefficient related to a concrete's ability to resist chloride ingress are compared-electrical resistance measurements [28], the rapid chloride permeability test [29], and accelerated penetration tests with chloride [30].

\section{Mixtures Properties and Samples Settings}

The evaluated experiment, calculations and results are part of the extensive campaign dealing with the durability of concrete structures. The laboratory experiments were conducted at the laboratories of Silesian University of Gliwice and VSB - Technical University of Ostrava. The set of laboratory samples consisted of seven large cylinders (diameter $150 \mathrm{~mm}$, height $300 \mathrm{~mm}$ ), six smaller cylinders (diameter $100 \mathrm{~mm}$, height 250, 200 and $100 \mathrm{~mm}$ ), four cubes (dimension $150 \mathrm{~mm}$ ), and three beams $(150 \times 150 \mathrm{~mm}$, length $450 \mathrm{~mm})$ for each mixture. (see Figure 1a).

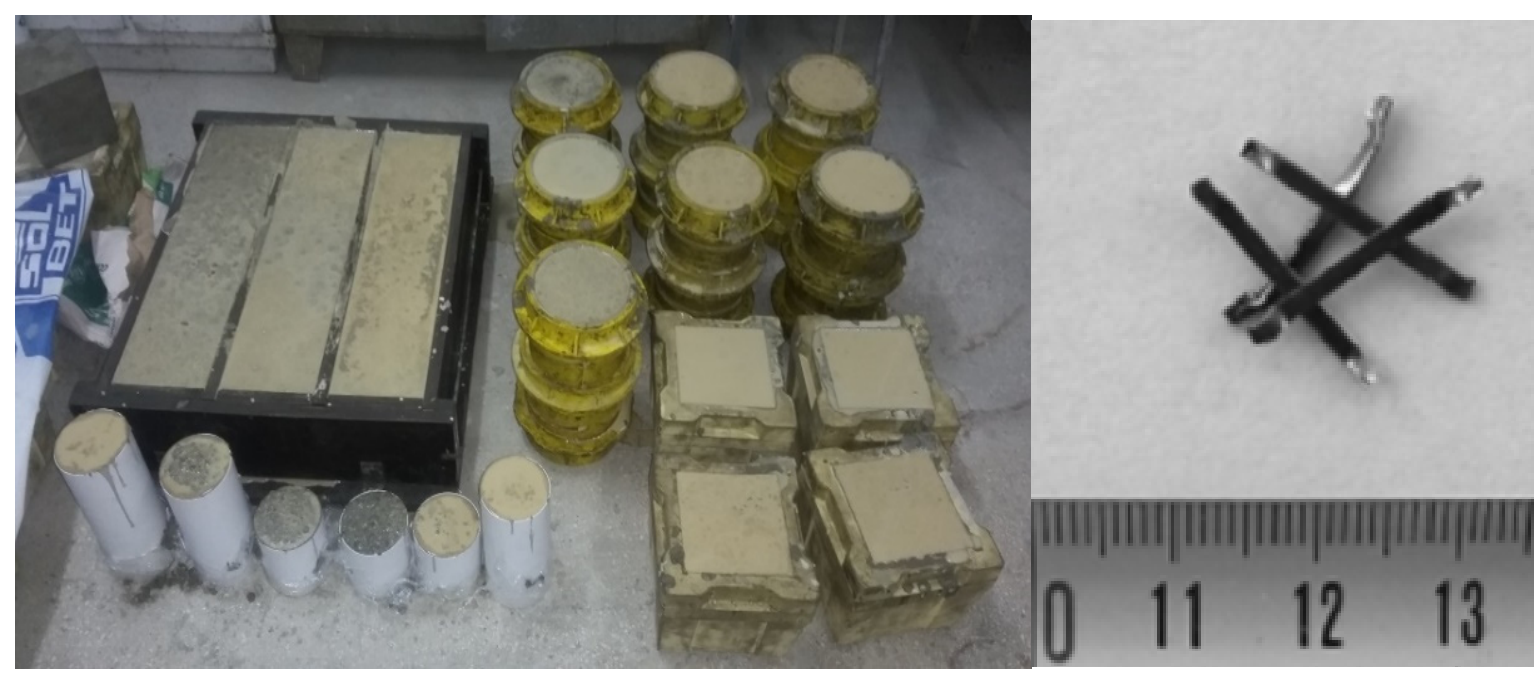

(a)

(b)

Figure 1. (a) Example of preparation of laboratory samples for one set of mixtures; (b) Steel fibres KE20/1.7—shape and dimension [31].

The reference concrete was formed from Ordinary Portland Cement (OPC). The Self-Compacting Concrete (SCC) with several values of added steel fibres- $0 \%, 1 \%$, and $2 \%$-was used in order to investigate the effect of fibres. The steel fibres were of type KE20/1.7 (see Figure 1b). The composition of the mixtures is shown in Table 1, and it is based on earlier SCC research at the SUT in Gliwice [1,19,31,32]. It needs to be noted that the cement applied in the SCC mixture had been in laboratory storage for more than two years, and partial hydration had already started. However, the concrete slump test was executed, and all mixtures have the same value of workability. 
Table 1. The concrete mixtures components [31] based on from Ordinary Portland Cement (OPC) and Self-Compacting Concrete (SCC) with steel fibres.

\begin{tabular}{ccccc}
\hline Mixture No. & OPC & SCC 0\% & SCC 1\% & SCC 2\% \\
\hline Cement type I 42.5 R & $313 \mathrm{~kg} / \mathrm{m}^{3}$ & & $490 \mathrm{~kg} / \mathrm{m}^{3}$ & \\
Water & $164 \mathrm{~kg} / \mathrm{m}^{3}$ & & $201 \mathrm{~kg} / \mathrm{m}^{3}$ & \\
Sand & $387 \mathrm{~kg} / \mathrm{m}^{3}$ & & $807 \mathrm{~kg} / \mathrm{m}^{3}$ & \\
River gravel & $1546 \mathrm{~kg} / \mathrm{m}^{3}$ & & $807 \mathrm{~kg} / \mathrm{m}^{3}$ & \\
Superplastificator & - & & $12.25 \mathrm{~kg} / \mathrm{m}^{3}$ & \\
Stabilizator & - & $1.96 \mathrm{~kg} / \mathrm{m}^{3}$ & \\
Steel Fibres & - & $80 \mathrm{~kg} / \mathrm{m}^{3}$ & $160 \mathrm{~kg} / \mathrm{m}^{3}$ \\
Water/cement ratio (W/C) & 0.52 & & 0.41 & \\
\hline
\end{tabular}

\section{Experimental Tests Range and Results}

A comprehensive range of tests comprised from basic mechanical properties; fracture test, as well as electrical resistance measurements [28], the rapid chloride permeability test [29], and accelerated penetration tests with chloride [30] were conducted.

\subsection{Mechanical Properties}

Compressive strength measurements were performed on standard cubes and cylinders, and also the tensile strength and modulus of elasticity were determined (see Figure 2) [31]. Firstly, it is possible to compare the results between an OCP and SCC mixture. In all properties, the SCC values are higher than the OPC. Because the SCC mixtures are not prepared in the way typical for high-performance concrete, it was expected that there would not be much difference in mechanical properties.

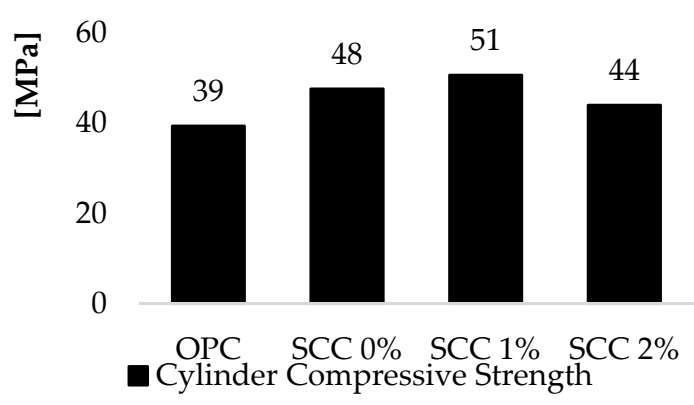

(a)

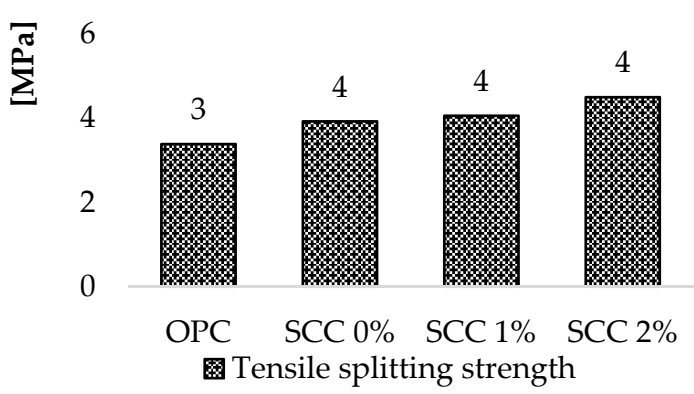

(c)

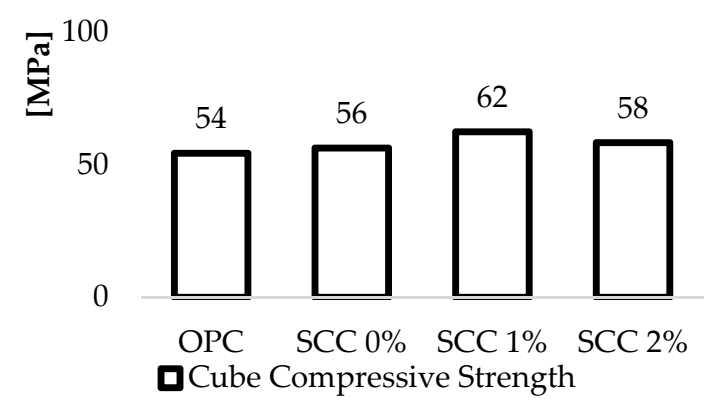

(b)

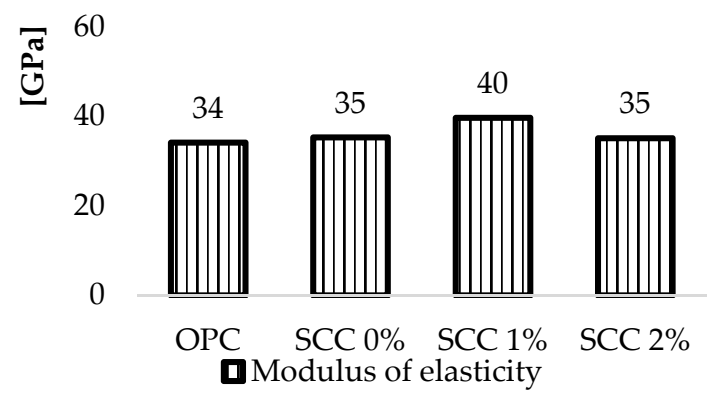

(d)

Figure 2. Results of material characteristics for all mixtures: (a) cylinder compressive strength; (b) cube compressive strength; (c) tensile spitting strength; (d) modulus of elasticity [31].

The second possibility is comparison related to the number of steel fibres in the SCC mixture. It shows that the higher the relative weight of the steel fibres, the higher the tensile splitting strength. 
However, other mechanical properties show that, when the amount of fibres exceeds a certain value, the properties no longer improve. The modulus of elasticity of the mixture SCC $1 \%$ is about $15 \%$ higher compared with other mixtures. This is in line with the typical limitation of the use of steel fibres up to $1.5 \%$ of the weight of concrete [33].

\subsection{Diffusion Properties}

The three procedures of detection of concrete diffusion coefficient were used. Two indirect electrochemical methods-rapid chloride permeability test (RCPT) [29] and surface measurement of electrical resistivity using Wenner probe (Resistivity) [28] — and a method based on the evaluation of chloride action—accelerated penetration tests with chloride (NTBuild 443) [30].

\subsubsection{Rapid Chloride Permeability Test}

The RCPT test [29] was conducted at the SUT in Gliwice. Due to the influence of fibre scattering, one cylindrical core for each mixture was cut into three slices of testing and marked Upper, Middle and Lower. All three slices from one cylinder were analysed. Test specimens were prepared and test procedures were performed according to ASTM C1202 [29]. The resulting passing charges, which indirectly evaluated the ability of the concrete to withstand an aggressive environment, are shown in Figure 3. The results show that there is a negligible difference in the reference mixture in terms of individual slices. There are some deviations (approx. 15\%) in SCC mixtures without wires, which can be influenced by shrinkage of the mixture. For a mixture of SCC with $1 \%$ of fibres, the differences are more significant, and the most significant differences are found for a mixture of $2 \%$ of fibres. The problem of the test is a rapid increase in temperature when using fibre reinforced concrete. From this point of view, the test is not an ideal solution for such an SCC-SFR mixture. Taking statistical variance into consideration, the average value was chosen for derivation of diffusion coefficients.

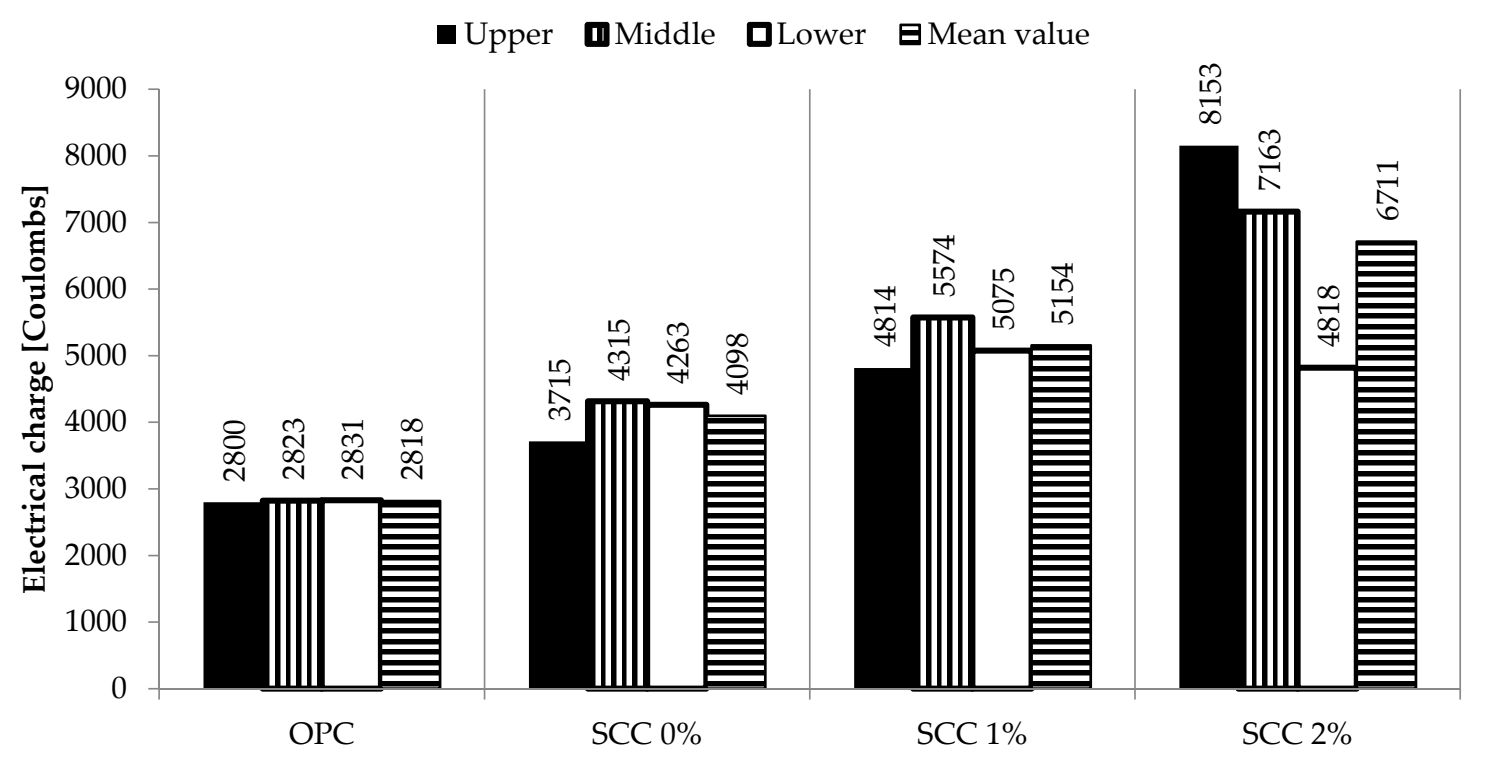

Figure 3. Results of the rapid chloride permeability test for three slices of testing and marked Upper, Middle and Lower, and mean values.

\subsubsection{Electrical Resistivity}

The standard test method for surface resistivity of concrete [28] is non-destructive; therefore, repeated measurements are possible to determine the time dependency of the diffusion. Unfortunately, this measurement method may have a relatively large variability, partly due to the heterogeneity of concrete and also due to the use of relatively uncontrollable contact conditions. It should be noted that the values of the volumetric resistivity were calculated from surface resistivity based on the 
relationship obtained from [34] and after that, to the resulting passing charges (equivalent to the results from RCPT) [35]. The test is non-destructive, and it is possible to measure the electrical properties during concrete ageing (see Figure 4). Results were partly published in [19,31].

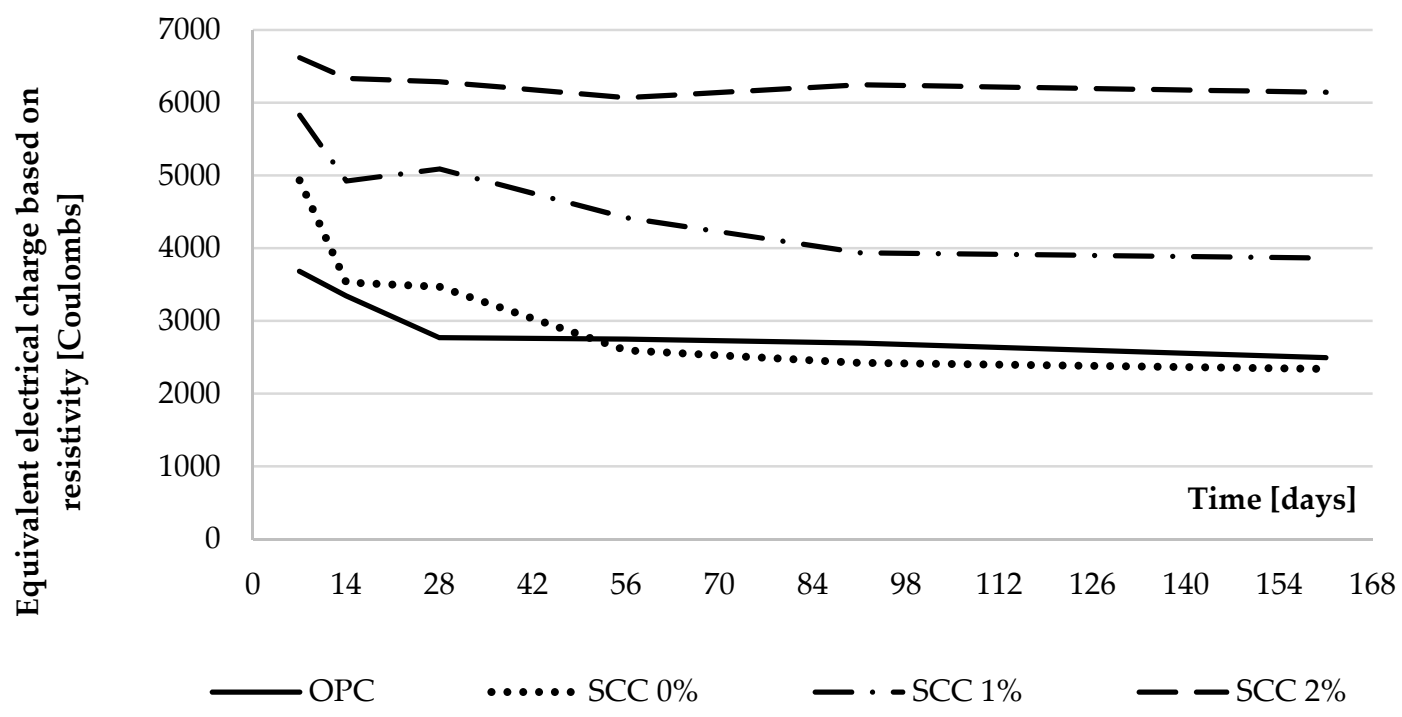

Figure 4. Results of time-dependent surface electrical resistivity of concrete.

Looking at the change of the passed charge, we may derive the following findings. The OPC mixture has standard behaviour whereby charge decreases over the concrete maturation, thus reflecting an improved ability of the concrete to withstand the aggressive environment. The SCC mixtures have similar behaviour, reflected in the similar shape of the curves. Although the relationship of shapes between 14 and 28 days are visible in all three SCC mixtures, their absolute difference cannot be considered as constant. If the influence of passed charge is based on the amount of added steel fibres, the shape of curves is proportional. However, there are also other influences that affect the readings, such as the initiation of corrosion of steel fibres.

\subsubsection{NTBuild 443}

The third test method was based on the modified NORDTEST NT Build 443 [13]. Concrete specimens were immersed in the saline solution (see Figure 5a), and then sampling of concrete powder in respective layers of chloride profile was conducted by drilling (see Figure $5 b$ ), thus the suitable period for chloride penetration was selected as 90 days. The concrete powder was subsequently evaluated for the presence of chloride ions in the laboratory, the obtained chloride profile was analysed, and the diffusion coefficient was calculated. The whole test procedure and the process of calculating the diffusion parameter are described in detail in [36]. 


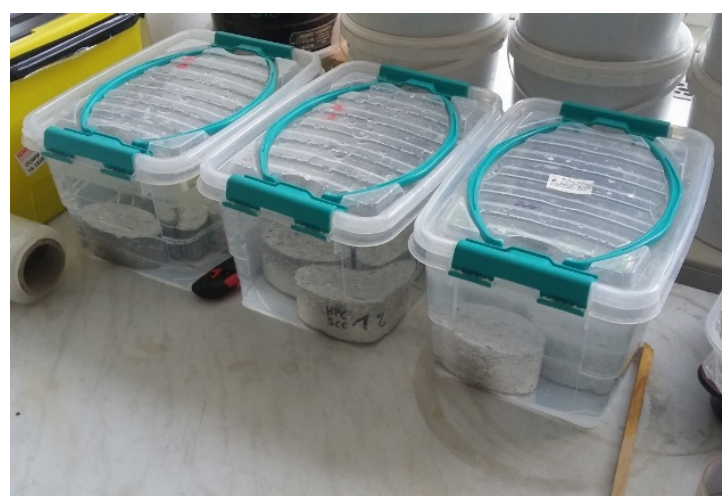

(a)

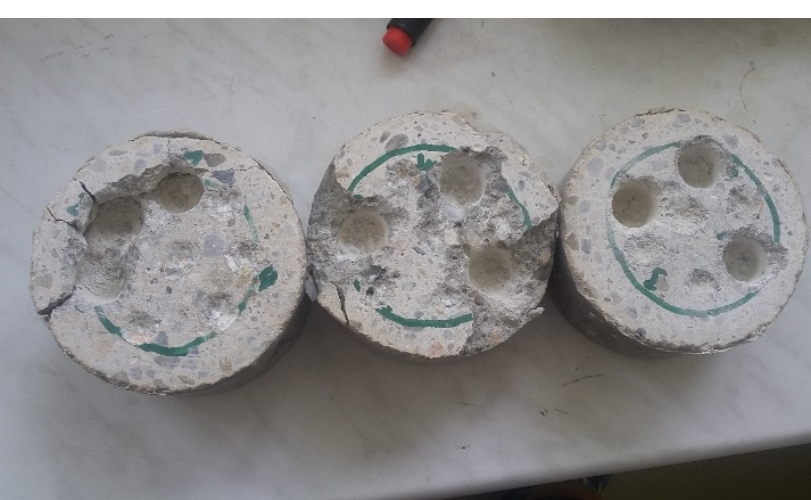

(b)

Figure 5. The process of the modified NORDTEST NT Build 443: (a) samples submerged in the chloride solution; (b) samples after drilling.

\section{Comparison of Diffusion Coefficients}

The resulting values of diffusion coefficients calculated from direct chloride profiling, and indirect electrochemical methods (RCPT and resistivity), are given in Figure 6 and in Table 2. The calculation of the diffusion coefficient $D_{c(t)}$ is based on the procedures given in [35,37] and is very well described in $[36,38,39]$. The number of analysed samples mean value and standard deviation is given in Table 2 . Figure 6 shows mean value and T-plot of minimum and maximum values.

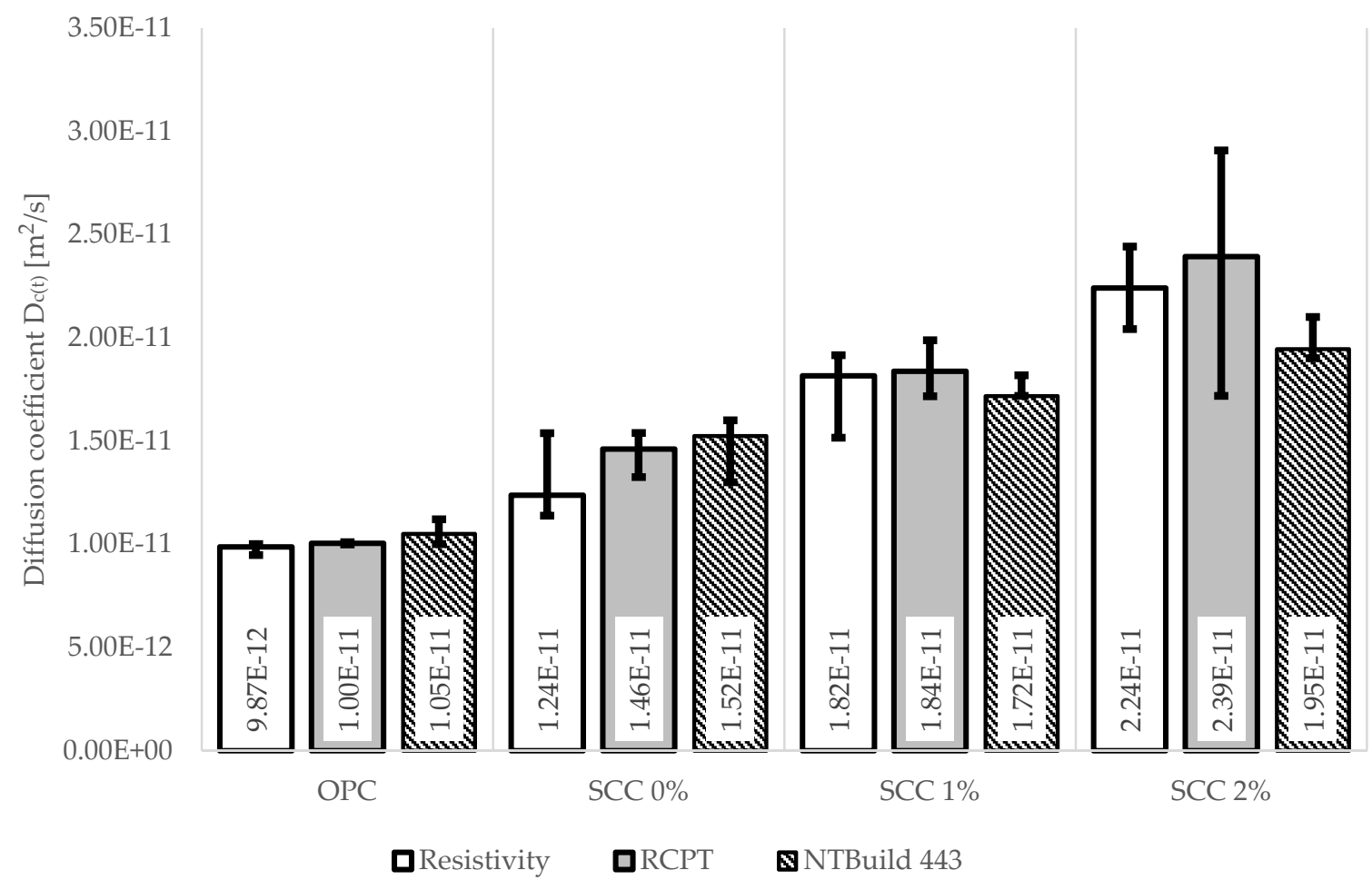

Figure 6. Diffusion coefficient $D_{c(t)}$ derived from surface resistivity, rapid chloride permeability test (RCPT) and chloride profile analysis (NTBuild 443). The minimum and maximum values are shown in the form of a T-graph. 
Table 2. Statistical data of diffusion coefficient $D_{\mathrm{c}}(t)$ derived from surface resistivity, rapid chloride permeability test (RCPT) and chloride profile analysis (NTBuild 443).

\begin{tabular}{ccccc}
\hline \multirow{2}{*}{ Mixture No. } & Method & Mean Value $\left[\mathrm{m}^{2} / \mathrm{s}\right]$ & $\begin{array}{c}\text { Standard Deviation } \\
{\left[\mathbf{m}^{2} / \mathbf{s}\right]}\end{array}$ & $\begin{array}{c}\text { Number of } \\
\text { Samples [-] }\end{array}$ \\
\hline \multirow{3}{*}{ OPC } & Resistivity & $9.80 \times 10^{-12}$ & $2.76 \times 10^{-13}$ & 4 \\
\cline { 2 - 5 } & RCPT & $1.00 \times 10^{-11}$ & $5.55 \times 10^{-14}$ & 3 \\
\cline { 2 - 5 } & NTBuild 443 & $1.05 \times 10^{-11}$ & $6.00 \times 10^{-13}$ & 3 \\
\hline \multirow{3}{*}{ SCC 0\% } & Resistivity & $1.24 \times 10^{-11}$ & $2.08 \times 10^{-12}$ & 4 \\
\cline { 2 - 5 } & RCPT & $1.46 \times 10^{-11}$ & $1.08 \times 10^{-12}$ & 3 \\
\hline \multirow{2}{*}{ SCC 1\% } & NTBuild 443 & $1.52 \times 10^{-11}$ & $1.51 \times 10^{-12}$ & 3 \\
\cline { 2 - 5 } & Resistivity & $1.82 \times 10^{-11}$ & $2.08 \times 10^{-12}$ & 4 \\
\hline & RCPT & $1.84 \times 10^{-11}$ & $1.36 \times 10^{-12}$ & 3 \\
\hline \multirow{2}{*}{ SCC 2\% } & NTBuild 443 & $1.72 \times 10^{-11}$ & $5.09 \times 10^{-13}$ & 3 \\
\cline { 2 - 5 } & Resistivity & $2.24 \times 10^{-11}$ & $2.00 \times 10^{-12}$ & 4 \\
\cline { 2 - 5 } & RCPT & $2.39 \times 10^{-11}$ & $5.96 \times 10^{-12}$ & 3 \\
\hline & NTBuild 443 & $1.95 \times 10^{-11}$ & $1.01 \times 10^{-12}$ & 3 \\
\hline
\end{tabular}

It should be noted that the values of the diffusion coefficient from resistivity are based on measurement at 28 days, from RCPT are based on measurement at 56 days, and from chloride profile, approximately 118 days. All these values are precisely determined according to the standards. It is worth noticing that the different level of maturation at the time of testing each method does not affect the comparison between specific mixture design that matters.

It is necessary to explain the meaning of the diffusion coefficient value. A diffusion coefficient closer to zero shows better diffusion resistance and hence better resistance to chloride ion penetration. Looking at the results of diffusion coefficients (Figure 6), the reference mixture (OPC) reports almost the same values for all methods. On the other hand, SCC $0 \%$ mixture has larger differences, but is still within limits of the inaccuracies of each method. In this case, the results of SCC $0 \%$ are worse than OPC, which is probably influenced by chemical additives. This is also because it is not a mixture that has been prepared as high resistance to the chloride. This is observed even though the mechanical properties (see Figure 2) are better for SCC mixtures.

Subsequent evaluation of mixtures with $1 \%$ and $2 \%$ fibres is interesting in terms of two hypothetical effects. The first effect is related to the electrical conductivity of steel wires in concrete. This effect should be reflected in two methods-RCPT and surface resistivity. The second effect is related to the real acceleration of diffusion along the fibres at the transition level with other material with respect to a possible influence of the microscopic void structure and porosity [6,40]. This should affect all three methods. Considering the possible scatter of measurement, it is possible to evaluate the effect of the amount of fibres on the two mentioned effects accordingly. For the purpose of comparison, SCC $0 \%$ mixture results were considered as the base values $(0 \%)$, and differences against the SCC $1 \%$ and $2 \%$ mixtures are shown in Figure 7. It is worth mentioning that the results of measurement of the RCPT is based on three cut out samples from one concrete cylinder. It can be seen, that the results are consistent within the OPC, SCC $0 \%, 1 \%$. However, the scatter for the $2 \%$ fibre content shows much higher scatter, indicating that this amount of steel fibres is too high. The finding is consistent with recommendation that the highest applicable amount of fibres is $1.5 \%$. It seems that the steel fibres were not spread out uniformly thought the cylinder. 


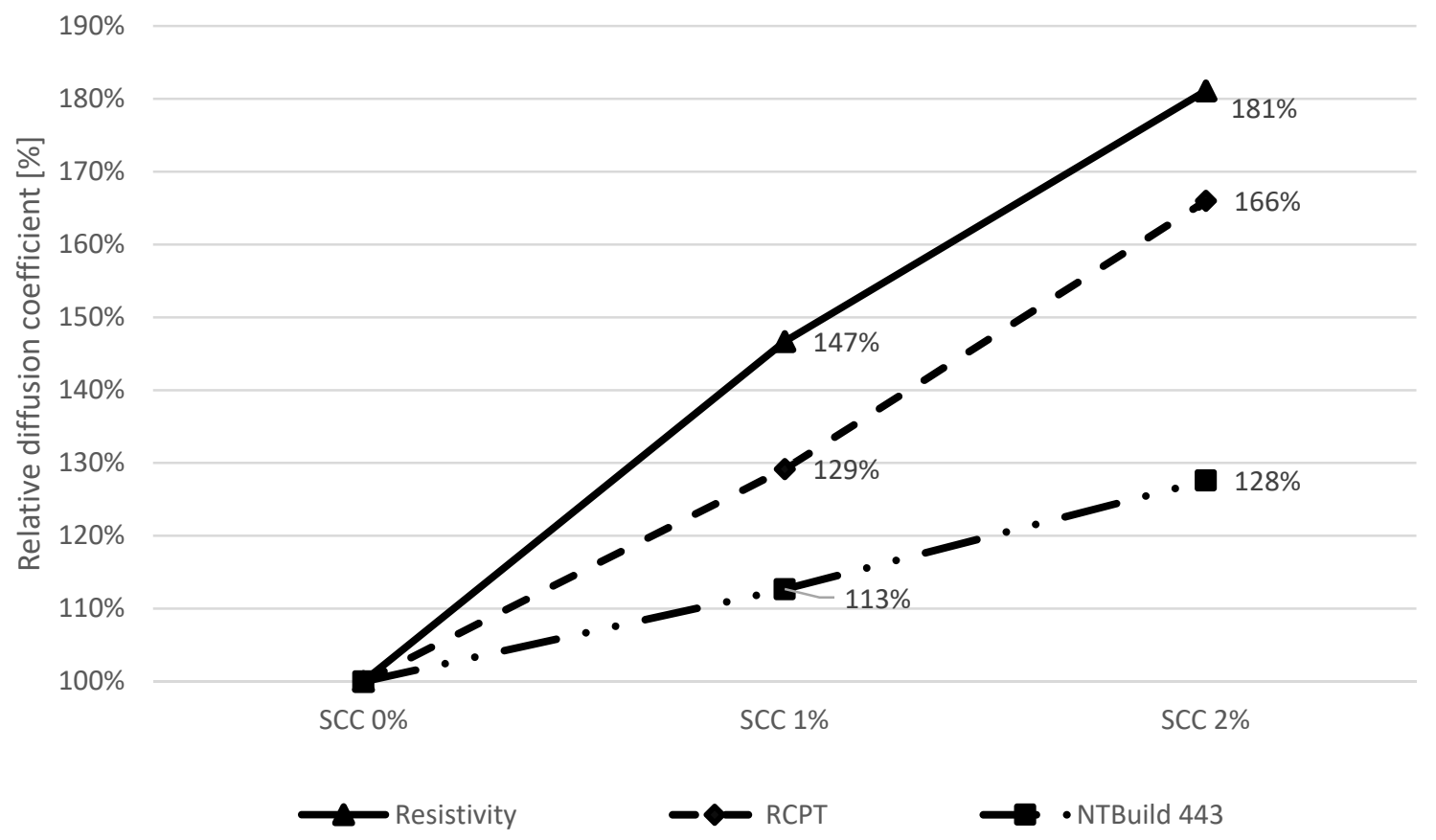

Figure 7. Percentile differences of the diffusion coefficient of the SCC $1 \%$ and $2 \%$ mixtures compared to mixture SCC $0 \%$.

Looking at the percentage results, the resistivity, RCPT and NTBuild 443 are noticeably affected by the amount of steel fibres as expected. The most significant influence is observed with a resistivity test, which is based on the direct current measurement, and the steel material is, therefore, a significant factor. The RCPT method is less affected but is also based on the charge and use of the penetration of a salt solution (in all samples of the same amount), so the effect of the amount of the steel fibres is lower. In the third method, the evaluation of the chloride profile, it is possible to consider only the effect of increased diffusion along the fibres or the possible influence of interface and micro-cracks along the fibres.

\section{Discussion and Conclusions}

The article evaluates durability related to concrete material parameters. There are relative values for cube and cylinder compression strength, tensile splitting strength, and modulus of elasticity. Three approaches are discussed for the computation of diffusion coefficient applicable to the numerical modelling of chloride ion ingress to concrete. Studied approaches are chloride profiling, electrical resistivity measurement, and rapid chloride permeability test. The comparison of the relatively fast method (resistivity and RCPT) for the evaluation of concrete ability to resist aggressive agents was conducted on the sample of self-compacting concrete. There was a correlation between the amount of steel fibres and conductivity, as expected. A larger amount of the steel fibres increases the calculated diffusion coefficient, both in electrochemical methods and in chloride profile evaluation. From this point of view, it is necessary to investigate, for example, porosity in further research. It needs to be proved if it causes some worse mechanical properties and, on the contrary, may tend to increase the results of all diffusion values (reducing the resistance against chloride penetration).

From the point of view of the amount of fibres in the concrete, it would be advisable to prepare more a graduated set of mixtures, e.g., $1.2 \%, 1.4 \%$, that can lead to finding the threshold at which the increasing properties change to decreasing. The experiment also confirmed that diffusion coefficients obtained by the electrochemical approaches are influenced by the steel fibres from both standpoints-electrical conductivity, as well as pore structure. 
Author Contributions: Conceptualization, P.K. and T.P.; methodology, T.P., P.L. and P.K.; software, P.L.; validation, P.K., P.L. and T.P.; data curation, P.L.; writing-original draft preparation, P.L.; writing-review and editing, P.K.; visualization, P.L.; project administration, P.K. All authors have read and agreed to the published version of the manuscript.

Funding: Financial support from VSB-Technical University of Ostrava by means of the Czech Ministry of Education, Youth and Sports through the Institutional support for conceptual development of science, research and innovations for the year 2020 is gratefully acknowledged.

Conflicts of Interest: The authors declare no conflict of interest.

\section{References}

1. Pajak, M.; Ponikiewski, T. Flexural behavior of self-compacting concrete reinforced with different types of steel fibers. Constr. Build. Mater. 2013, 47, 397-408. [CrossRef]

2. Gołaszewski, J. Influence of cement properties on new generation superplasticizers performance. Constr. Build. Mater. 2012, 35, 586-596. [CrossRef]

3. Goodier, C.I. Development of self-compacting concrete. Proc. Inst. Civ. Eng. Struct. Build. 2003, 156, $405-414$. [CrossRef]

4. Zhu, W.; Bartos, P.J.M. Uniformity of in situ properties of self-compacting concrete in full-scale structural elements. Cem. Concr. Res. 2001, 23, 57-64. [CrossRef]

5. Okamura, H.; Ozawa, K. Self-Compacting High Performance Concrete. Struct. Eng. Int. J. Int. Assoc. Bridg. Struct. Eng. 1996, 6, 269-270. [CrossRef]

6. Łaźniewska-Piekarczyk, B. Effect of viscosity type modifying admixture on porosity, compressive strength and water penetration of high performance self-compacting concrete. Constr. Build. Mater. 2013, 48, 1035-1044. [CrossRef]

7. Abrishambaf, A.; Barros, J.A.O.; Cunha, V.M.C.F. Tensile stress-crack width law for steel fibre reinforced self-compacting concrete obtained from indirect (splitting) tensile tests. Cem. Concr. Compos. 2015, 57, 153-165. [CrossRef]

8. Mo, K.H.; Yap, K.K.Q.; Alengaram, U.J.; Jumaat, M.Z. The effect of steel fibres on the enhancement of flexural and compressive toughness and fracture characteristics of oil palm shell concrete. Constr. Build. Mater. 2014, 55, 20-28. [CrossRef]

9. Ponikiewski, T.; Katzer, J. Fresh Mix Characteristics of Self- Compacting Concrete Reinforced by Fibre. Period. Polytech. Civ. Eng. 2017, 61, 226-231. [CrossRef]

10. Mogaveera, G.; Umesh, S.S. Anand, Research on the Strength parameters of poly propylene fiber reinforced concrete and steel fiber reinforced concrete, V.R. Int. J. Recent Technol. Eng. 2019, 8, 954-957.

11. da Silva, G.C.S.; Christ, R.; Pacheco, F.; de Souza, C.F.N.; Gil, A.M.; Tutikian, B.F. Evaluating steel fiber-reinforced self-consolidating concrete performance. Struct. Concr. 2019. [CrossRef]

12. RilemT.C. 162-TDF. Test and design methods for steel fibre reinforced concrete - Bending test. Mater. Struct. Constr. 2002, 35, 579-582. [CrossRef]

13. BS EN 14651:2005 Test Method for Metallic Fibre. Concrete-Measuring the Flexural Tensile Strength; British Standards Institution: London, UK, 2005.

14. Katzer, J.; Domski, J. Quality and mechanical properties of engineered steel fibres used as reinforcement for concrete. Constr. Build. Mater. 2012, 34, 243-248. [CrossRef]

15. Alberti, M.G.; Enfedaque, A.; Gálvez, J.C. Fibre reinforced concrete with a combination of polyolefin and steel-hooked fibres. Compos. Struct. 2017, 171, 317-325. [CrossRef]

16. Ahmad, H.; Hashim, M.H.M.; Hamzah, S.H.; Bakar, A.A. Steel Fibre Reinforced Self-Compacting Concrete (SFRSC) performance in slab application: A review. AIP Conf. Proc. 2016, 1774, 030024.

17. Kayali, O.; Ahmed, M.S. Assessment of high volume replacement fly ash concrete-concept of performance index. Constr. Build. Mater. 2013, 39, 71-76. [CrossRef]

18. Ghosh, P.; Hammond, A.; Tikalsky, P.J. Prediction of Equivalent Steady State Chloride Diffusion Coefficients. ACI Mater. J. 2011, 108, 88-94.

19. Lehner, P.; Konecny, P.; Ponikiewski, T. Experimental and Numerical Evaluation of SCC Concrete Durability Related to Ingress of Chlorides. AIP Conf. Proc. 2018, 176, 150012.

20. Ghosh, P.; Konečný, P.; Lehner, P.; Tikalsky, P.J.P.J. Probabilistic time-dependent sensitivity analysis of HPC bridge deck exposed to chlorides. Comput. Concr. 2017, 19, 305-313. [CrossRef] 
21. Novák, D.; Vořechovský, M.; Teplý, B. FReET: Software for the statistical and reliability analysis of engineering problems and FReET-D: Degradation module. Adv. Eng. Softw. 2014, 7, 179-192. [CrossRef]

22. Vořechovská, D.; Teplý, B.; Šomodíková, M. Chloride Ion Ingress Modelling and the Reliability of Concrete Structures. In Proceedings of the 12th International Conference on Structural Safety and Reliability, Vienna, Austria, 6-10 August 2017; pp. 6-10.

23. Bentz, E.C.; Thomas, M.D.A. Life-365 Service Life Prediction Model: And Computer Program for Predicting the Service Life and Life-Cycle Cost of Reinforced Concrete Exposed to Chlorides. Life-365 User Man. 2013, $1-87$.

24. Parant, E.; Pierre, R.; le Maou, F. Durability of a multiscale fibre reinforced cement composite in aggressive environment under service load. Cem. Concr. Res. 2007, 37, 1106-1114. [CrossRef]

25. Berrocal, C.G.; Lundgren, K.; Löfgren, I. Corrosion of Steel Bars Embedded in Fibre Reinforced Concrete under Chloride Attack: State-of-the-Art. Cem. Concr. Res. 2016, 80, 69-85. [CrossRef]

26. Azarsa, P.; Gupta, R. Electrical resistivity of concrete for. durability evaluation: A review. Adv. Mater. Sci. Eng. 2017, 2017, 1-30. [CrossRef]

27. Berrocal, C.; Lundgren, K.; Löfgren, I. Influence of Steel Fibres on Corrosion of Reinforcement in Concrete in Chloride Environments: A Review. Fibre Concr. 2013, 80, 1-10.

28. AASHTO TP95, Standard Method of Test for Surface Resistivity Indication of Concrete's Ability to Resist Chloride Ion Penetration; American Society for Testing and Materials: Washington, DC, USA, 2014; p. 10.

29. ASTM C1202; American Society for Testing and Materials: Philadelphia, PA, USA, 2012; pp. 1-8.

30. Nordtest NTBuild 443. Nordtest Method: Accelerated Chloride Penetration into Hardened Concrete; Nordtest: Esbo, Finland, 1995.

31. Lehner, P.; Konečnỳ, P.; Ponikiewski, T. Relationship between Mechanical Properties and Conductivity of SCC Mixtures with Steel Fibres. In Proceedings of the Central European Civil Engineering Meeting, Research and Modelling in Civil Engineering 2018, Koszalin, Poland, 4-8 June 2018.

32. Sucharda, O.; Pajak, M.; Ponikiewski, T.; Konecny, P. Identification of mechanical and fracture properties of self-compacting concrete beams with different types of steel fibres using inverse analysis. Constr. Build. Mater. 2017, 138, 263-275. [CrossRef]

33. Manoharan, S.V.; Anandan, S. Steel fibre reinforcing characteristics on the size reduction of fly ash based concrete. Adv. Civ. Eng. 2014, 2014, 1-11. [CrossRef]

34. Morris, W.; Moreno, E.I.; Sagüés, A.A. Practical evaluation of resistivity of concrete in test cylinders using Wenner array probe. Cem. Concr. Res. 1996, 26, 1779-1787. [CrossRef]

35. Ghosh, P. Computation of Diffusion Coefficients and Prediction of Corrosion Initiation in Concrete Structures. Ph.D. Thesis, The University of Utah, Salt Lake City, UT, USA, 2011.

36. Lehner, P.; Turicová, M.; Konečnỳ, P. Comparison of selected methods for measurement of the concrete electrical resistance to chloride penetration. ARPN J. Eng. Appl. Sci. 2017, 12, 937-944.

37. Lu, X. Application of the Nernst-Einstein equation to concrete. Cem. Concr. Res. 1997, 27, 293-302. [CrossRef]

38. Lehner, P.; Ghosh, P.; Konečný, P. Statistical analysis of time dependent variation of diffusion coefficient for various binary and ternary based concrete mixtures. Constr. Build. Mater. 2018, 183, 75-87. [CrossRef]

39. Konečný, P.; Lehner, P.; Ponikiewski, T.; Miera, P. Comparison of Chloride Diffusion Coefficient Evaluation Based on Electrochemical Methods. Procedia Eng. 2017, 190, 193-198. [CrossRef]

40. Roubin, E.; Colliat, J.B.; Benkemoun, N. Meso-scale modeling of concrete: A morphological description based on excursion sets of Random Fields. Comput. Mater. Sci. 2015, 102, 183-195. [CrossRef]

(C) 2020 by the authors. Licensee MDPI, Basel, Switzerland. This article is an open access article distributed under the terms and conditions of the Creative Commons Attribution (CC BY) license (http://creativecommons.org/licenses/by/4.0/). 